\title{
USO DE OBJETO EDUCACIONAL DIGITAL NA PERSPECTIVA DA EDUCAÇÃO ESPECIAL: RELATO DE UMA PRÁTICA PEDAGÓGICA
}

\author{
USO DEL OBJETO EDUCACIONAL DIGITAL EN LA PERSPECTIVA DE LA \\ EDUCACIÓN ESPECIAL: RELATO DE UNA PRÁCTICA PEDAGÓGICA
}

\section{USE OF EDUCATIONAL OBJECT ON THE PERSPECTIVE OF THE SPECIAL EDUCATION: REPORT ABOUT A PEDAGOGIC PRATICE}

\author{
Adriana Garcia GONÇALVES ${ }^{1}$ \\ Alessandra Daniele Messali PICHARILLO ${ }^{2}$ \\ Mariana Cristina PEDRINO 3
}

RESUMO: O presente estudo teve como objetivo descrever uma experiência de utilização de um software educativo para todos os alunos e, especialmente, para aluno com Transtorno do Espectro Autista matriculado em sala comum da educação infantil. Foi realizado uma pesquisa no Banco internacional de Objetos Educacionais no link acerca da Educação Infantil, em que foi feita a escolha pelo software denominado JClic para a realização da atividade pedagógica. A atividade foi realizada em uma sala comum na educação infantil com vinte e dois alunos na faixa etária entre quatro e cinco anos e que havia dois alunos com maior dificuldade de comunicação, sendo o aluno G. diagnosticado com autismo e o aluno $\mathrm{M}$. com dificuldades de comunicação na forma oral. Os dados obtidos foram analisados de forma qualitativa tendo como base a observação e registro realizados pela pesquisadora e seguindo a metodologia de relato de estudos de caso. O software JClic, como objeto de aprendizagem, foi utilizado neste estudo, porém, é de extrema importância relatar que a prática pedagógica, mediada pelo professor, potencializou e contribuiu para expressividade e criatividade de alunos matriculados na educação infantil, especialmente para aqueles com dificuldades de comunicação, como no caso o aluno com TEA.

PALAVRAS-CHAVE: Educação especial. Objeto educacional. Software. Ensino e aprendizagem.

RESUMEN: El presente estudio tuvo como objetivo describir una experiencia de utilización de un software educativo para todos los alumnos y, especialmente, para alumno con Trastorno del Espectro Autista matriculado en clase común de educación infantil. Fue realizada una investigación en el Banco Internacional de Objetos Educacionales en el link acerca de la Educación Infantil, en que fue hecha la elección

\footnotetext{
${ }^{1}$ Universidade Federal de São Carlos (Ufscar), São Carlos - SP - Brasil. Departamento de Psicologia, Curso de Licenciatura em Educação Especial e Programa de Pós Graduação em Educação Especial PPGEEs. E-mail: adrigarcia33@yahoo.com.br.

${ }^{2}$ Universidade Federal de São Carlos (Ufscar), São Carlos - SP - Brasil. Licenciada em Educação Especial. E-mail: alessandrapicharillo@outlook.com.

${ }^{3}$ Universidade Federal de São Carlos (Ufscar), São Carlos - SP - Brasil. Mestre em Educação E-mail: maripedrino@gmail.com.
}

RPGE - Revista on line de Política e Gestão Educacional, Araraquara, v. 21, n. esp.3, p. 1726-1735, dez., 2017. 
por el software denominado JClic para la realización de la activdad pedagógica. La actividad fue realizada en uma clase común en la educación especial infantil con veintidos alumnos con edad entre cuatro y cinco años y que había dos alumnos con una gran dificultad de comunicación, siendo el alumno $G$. diagnosticado con autismo y el alumno M. con dificultades de comunicación en la manera oral. Los datos obtidos fueron analisados de manera qualitativa tenendo como base la observación y registro realizados por la investigadora y siguiendo la metodología de relato de estudios de caso. El software JClic, como objeto del aprendizaje, mediado por el profesor, potencializó y contribuyó para la expresividad y creatividad de alumnos matriculados en la educación infantil, especialmente para aquellos con dificultades de comunicación, como en el caso del alumno con TEA.

PALABRAS CLAVE: Educación especial. Objeto educacional. Software. Enseñanza y aprendizaje.

ABSTRACT: This research aimed to describe an experience of using educational software for all students, and especially for students with Autism Spectrum Disorder enrolled in classroom early childhood education. A research was carried out in the international repository of Educational Objects on the link on the Early Childhood Education, it was made the choice of software called JClic for the realization of educational activity. The activity was held in a classroom in kindergarten twenty-two students aged between four and five years and had two students with greater difficulty in communication, and the student $G$. diagnosed with autism and student with $M$. communication difficulties in oral form. The data were analyzed qualitatively based on the observation and recording performed by the researcher and following the reporting methodology of case studies. The JClic software, such as learning object was used in this study, however, is extremely important report that the teaching practice, mediated by the teacher, potentiated and contributed to expressiveness and creativity of students enrolled in early childhood education, especially for those with difficulties communication, such as the student with Autism Spectrum Disorder.

KEYWORDS: Special education. Educational object. Software. Teaching and learning.

\section{Introdução}

De acordo com a quinta edição do Manual de Diagnóstico e Estatística dos Transtornos Mentais (DSM-5) do ano de 2014, os alunos diagnosticados com Transtorno do Espectro Autista (TEA) podem apresentar déficits em duas grandes áreas que são: comunicação social e comportamentos restritos e repetitivos. Quanto ao grau de comprometimento, pode variar em três níveis de gravidade: exigindo apoio muito substancial, exigindo apoio substancial e exigindo apoio (AMERICAN PSYCHIATRIC ASSOCIATION, 2014).

RPGE - Revista on line de Política e Gestão Educacional, Araraquara, v. 21, n. esp.3, p. 1726-1735, dez., 2017. 
Os déficits na comunicação social podem ser na reciprocidade ou na interação social, dificultando uma fala com significado e/ou a compreensão do que lhe é dito. Essa característica pode dificultar o estabelecimento de relacionamento social nos diversos ambientes, inclusive no ambiente escolar. Ainda pode gerar impedimentos nos momentos lúdicos, uma vez que ocorram barreiras na comunicação e interação com os demais alunos. Quanto aos comportamentos restritos e repetitivos, podem ser observados em movimentos motores repetitivos (estereotipias), fixação por objetos, alimentos e cores, dificuldade em modificar a rotina, e ainda, hiper ou hiporreatividade a estímulos sensoriais como dor, temperatura, sons entre outros. O comprometimento nessa área pode dificultar permanência do aluno no ambiente escolar caso não encontre quais são os estímulos aversivos e os retire. Contudo pode ocorrer de o aluno ser sensível a um fator que não possa ser totalmente alterado, havendo necessidade de investigação para encontrar a melhor maneira de organizar as contingências (AMERICAN PSYCHIATRIC ASSOCIATION, 2014).

O Decreto $\mathrm{n}^{\mathrm{o}} 7.611$ de 17 de novembro de 2011, que Dispõe sobre a Educação Especial, o Atendimento Educacional Especializado (AEE) e dá outras providências, expõe em seu Art. $1^{\circ}$ que é dever do Estado com a educação das pessoas público-alvo da educação especial será efetivado de acordo a: I - garantia de um sistema educacional inclusivo em todos os níveis, sem discriminação e com base na igualdade de oportunidades.

Ainda em seu parágrafo primeiro, o Decreto define público alvo da educação especial: as pessoas com deficiência, com transtornos globais do desenvolvimento e com altas habilidades ou superdotação (BRASIL, 2011).

A política de inclusão escolar é um movimento mundial que apresenta inúmeros desafios para sua efetivação, uma vez que há uma dicotomia entre o processo de globalização mundial que cria uma interdependência entre os países, mas, ao mesmo tempo, evidencia as diferenças entre os povos. Isso gera maiores desigualdades econômicas, tecnológicas e educacionais entre os países (MATOS; MENDES, 2014). Diante do fato, muitas discussões foram postas, o que gerou documentos norteadores, como por exemplo, a Declaração de Salamanca (UNESCO, 1994) para garantir o debate acerca do imperativo de universalização da educação básica, em que o aluno público alvo da educação especial tem direito à escolarização em espaços mais inclusivos, em lugares de direito numa sociedade de aprendizagem.

RPGE - Revista on line de Política e Gestão Educacional, Araraquara, v. 21, n. esp.3, p. 1726-1735, dez., 2017. 
No Brasil, há necessidade de reformas educacionais amplas com alterações nas estruturas físicas das escolas, bem como investimentos para oferta de equipamentos e recursos tecnológicos, no sentido de garantir maior autonomia e qualidade no ensino dos alunos público alvo da educação especial. Por conseguinte, toda a comunidade escolar se beneficiará com o processo de inclusão escolar com uma política educacional mais democrática.

Em relação aos recursos tecnológicos digitais que disponibilizam ferramentas multimídias, vale ressaltar que o professor quando os utiliza, de forma planejada, podem favorecer o desenvolvimento das atividades necessárias para suscitar o desenvolvimento cognitivo e garantir maior autonomia dos alunos.

Para os alunos público alvo da educação especial as tecnologias de informação e comunicação podem beneficiar o desenvolvimento e aprendizagem de conteúdos escolares, uma vez que os recursos tecnológicos digitais têm características atrativas e dinâmicas. Quando bem utilizados, favorecem a compreensão da atividade proposta devido a instrumentalização auditiva e visual que o recurso digital planejado pode propiciar ao aluno (PEDRO, 2012).

Diante disso, o presente estudo teve como objetivo descrever uma experiência de utilização de um software educativo para todos os alunos e, especialmente, para aluno com TEA matriculado em sala comum da educação infantil.

A Educação Infantil, primeiro nível da Educação Básica no Brasil, é norteada pelo Referencial Curricular Nacional para a Educação Infantil, documento apresentado em três volumes: Introdução, Formação Pessoal e Social, e Conhecimento de Mundo. O conteúdo desses volumes busca orientar o professor em seu planejamento para que atinja o desenvolvimento dos alunos nas áreas de: Identidade e Autonomia, Movimento, Música, Artes Visuais, Linguagem Oral e Escrita, Natureza e Sociedade e Matemática. O documento é um guia para a base de discussões nos planejamentos de cada instituição, respeitando-se a diversidade de cada localidade (BRASIL, 1998).

O documento citado traz objetivos distintos para cada grande área do desenvolvimento, no entanto, de modo geral visa promover o desenvolvimento e a autonomia do aluno, buscando por meio da interdisciplinaridade, se utilizar de atividades de um determinado eixo para conquistar um desenvolvimento que contemple os demais. Por exemplo, uma atividade no eixo da música que objetive o desenvolvimento da capacidade de expressão e interpretação, repertórios essenciais à área da comunicação e cognição (BRASIL, 1998).

RPGE - Revista on line de Política e Gestão Educacional, Araraquara, v. 21, n. esp.3, p. 1726-1735, dez., 2017. 
De acordo com o Referencial Curricular Nacional da Educação Infantil,

Educar significa, portanto, propiciar situações de cuidado, brincadeiras e aprendizagem orientadas de forma integrada e que possam contribuir para o desenvolvimento das capacidades infantis de relação interpessoal de ser e estar com os outros em uma atitude básica de aceitação, respeito e confiança, e o acesso, pelas crianças aos conhecimentos mais amplos da realidade social e cultural (BRASIL, 1998, p. 23).

O brincar e a brincadeira estão atrelados à Educação Infantil, não como um momento para "passar o tempo", recrear, representando uma atividade sem propósito, mas como um recurso para potencializar a exploração e a construção do conhecimento (OLIVEIRA, 2000).

Nesse sentido, cabe ao educador planejar atividades que motivem as crianças e potencialize suas múltiplas aprendizagens, além de possibilitar a maior interação e cooperação entre os pares.

Pensando nisso, e considerando a matrícula de duas crianças público alvo da Educação Especial na sala regular de uma escola de Educação Infantil em um município de médio porte interior de São Paulo, as pesquisadoras procuraram planejar e aplicar uma atividade pedagógica, com uso de um software educativo, que será descrita no desenvolvimento do trabalho, a seguir.

\section{Descrição do trabalho desenvolvido}

A atividade foi planejada no decorrer das inserções da disciplina de Prática de Ensino e Estágio Supervisionado III do Curso de Licenciatura em Educação Especial da Universidade Federal de São Carlos (UFSCar), realizado no primeiro semestre do ano de 2016 em uma escola municipal de Educação Infantil. Desta forma, a atividade foi planejada pelas pesquisadoras, mas aplicada por apenas uma pesquisadora que estava realizando o estágio supervisionado.

A intenção de utilizar um objeto educacional digital para uma inserção e intervenção na escola estagiada surgiu no decorrer das aulas da disciplina "Tecnologias aplicadas à Educação Especial I: Informação e comunicação"4.

4 Disciplina ofertada aos alunos do $7^{\circ}$ perfil do Curso de Licenciatura em Educação Especial da Universidade Federal de São Carlos, no primeiro semestre do ano de 2016, pela Prof ${ }^{a}$ Dr $^{\text {a }}$ Adriana Garcia Gonçalves.

RPGE - Revista on line de Política e Gestão Educacional, Araraquara, v. 21, n. esp.3, p. 1726-1735, dez., 2017. 
Durante as aulas, a pesquisadora teve a oportunidade de conhecer o Banco Internacional de Objetos Educacionais ${ }^{5}$, um repositório que possui objetos educacionais de acesso público, em diferentes formatos e para todos os níveis de ensino. O banco está organizado em links pelas etapas, níveis e modalidades de ensino da seguinte forma: educação infantil, ensino fundamental, ensino médio, educação profissional, educação superior e modalidades de ensino.

Há muitas definições para o termo "objeto educacional" ou "objeto de aprendizagem", mas adotamos a concepção de Audino e Nascimento (2010):

[...] definimos objetos de aprendizagem como sendo recursos digitais dinâmicos, interativos e reutilizáveis em diferentes ambientes de aprendizagem elaborados a partir de uma base tecnológica. Desenvolvidos com fins educacionais, eles cobrem diversas modalidades de ensino [...]; diversos campos de atuação [...].

[...] entendemos que os objetos de aprendizagem são recursos capazes de proporcionar, mediante a combinação de diferentes mídias digitais, situações de aprendizagem em que o educador assuma o caráter de mediador e o aluno o caráter de sujeito ativo dentro do processo de ensino e aprendizagem (AUDINO; NASCIMENTO, 2010, p. 141)

Desta forma, após pesquisa nos objetos educacionais contidos no link acerca da Educação Infantil, foi feita a escolha pelo software denominado JClic para a realização da atividade pedagógica. O critério de seleção foi motivado, pois o software apresenta uma interface simples e atrativa para a faixa etária; por estar adequado às atividades pedagógicas que já estavam sendo trabalhadas com os alunos - características de alguns animais; por estimular a participação de todos os educandos por meio do recurso da gravação/imitação de sons e por possibilitar a aprendizagem do conteúdo de modo interativo.

Outro fator que contribuiu para a escolha do software educativo foi a constatação de que o uso de recursos das Tecnologias da Informação e Comunicação (TICs) tem contribuído para que as pessoas com deficiência sejam beneficiadas no seu processo de desenvolvimento e de aprendizagem, tendo aprendizagens mais significativas (PEDRO, 2012).

A atividade teve como objetivo geral descrever uma experiência de utilização de um software educativo para todos os alunos e, especialmente, para aluno com TEA matriculado em sala comum da educação infantil. Os objetivos específicos foram:

${ }^{5}$ Disponível em: <http://objetoseducacionais2.mec.gov.br/handle/mec/17439>. Acesso em: 10 set. 2016.

RPGE - Revista on line de Política e Gestão Educacional, Araraquara, v. 21, n. esp.3, p. 1726-1735, dez., 2017. 
possibilitar a interação entre todos os alunos, desenvolver a atenção dos alunos para ouvir o som emitido por alguns animais e tentar imitá-lo.

A atividade foi realizada com vinte e dois alunos com faixa etária entre quatro e cinco anos, matriculados e frequentes na Fase V - penúltima etapa da Educação Infantil - sendo o aluno G. diagnosticado com autismo e o aluno M. com dificuldades de comunicação oralizada.

O software JClic foi apresentado aos alunos no notebook da pesquisadora. Foram demonstrados os animais contidos no jogo selecionado e os respectivos sons que emitem. Em seguida, a pesquisadora explicou os procedimentos para a realização da atividade: um por um os alunos viriam até a mesa para escolher um animal ilustrado no jogo. Ouviriam o som que o animal emite e, em seguida, imitariam o mesmo som para ser gravado. Depois disso, a pesquisadora reproduziria as gravações para que todos pudessem apreciá-las.

Após a explicação, a atividade teve seu início e decorreu conforme planejado.

\section{Resultados obtidos}

Os dados obtidos foram analisados de forma qualitativa tendo como base a observação e registro realizados pela pesquisadora e seguindo a metodologia de relato de estudos de caso (GIL, 2010).

Vale destacar que na pesquisa qualitativa, há uma preocupação com o processo como o problema se manifesta nas atividades, nos procedimentos e nas interações - e uma tentativa de capturar a "perspectiva dos participantes" (LÜDKE; ANDRÉ, 1986).

Pode-se perceber no desenvolvimento da atividade que houve muita cooperação entre os alunos, que permaneceram atentos e em silêncio para ouvir as escolhas dos pares e as gravações de suas imitações.

Quando o aluno se aproximava e a pesquisadora perguntava qual animal ele queria imitar, deveria responder oralmente sua intenção. Esse objetivo foi atingido inclusive com os alunos G., que escolheu cachorro, e M., que escolheu gato. Esses alunos normalmente não se comunicavam oralmente com os demais colegas.

$\mathrm{O}$ aluno $\mathrm{M}$ foi um dos últimos a ser chamado intencionalmente, para que tivesse oportunidade de observar os colegas e diminuir o impacto da novidade de uma atividade aplicada pela pesquisadora. Durante o tempo de espera, a pesquisadora conseguiu observar que o aluno ameaçou por várias vezes se levantar a cada troca de participante,

RPGE - Revista on line de Política e Gestão Educacional, Araraquara, v. 21, n. esp.3, p. 1726-1735, dez., 2017. 
o que deu indícios de que estava interessado em participar. Quando foi chamado à mesa, veio imediatamente.

Apenas uma aluna se recusou a participar, mesmo sendo oferecidas alternativas para que ela participasse apenas com a professora regente ou em outro ambiente.

Ao final da atividade, a professora regente sugeriu que fossem escolhidos outros animais para que toda a turma imitasse, de forma coletiva e ao mesmo tempo, assim como também gravaram o som dos animais escolhidos. Os alunos participaram e bateram palmas depois que ouviram a gravação da imitação. A professora relatou para a pesquisadora que achou a atividade positiva e gostaria que a escola promovesse mais acesso a esse tipo de atividade.

Nesse sentindo, podemos compreender que o uso do objeto educacional reforçou a interação das crianças com a pesquisadora, bem como potencializou suas aprendizagens, como mencionam Audino e Nascimento (2010):

\begin{abstract}
Atualmente, os objetos de aprendizagem podem ser encarados como materiais importantes no processo de ensino e aprendizagem, pois nos fornecem a capacidades de simular e animar fenômenos, entre outras características, assim como, reutilizá-los em vários outros ambientes de aprendizagem. [...] Além disso, eles surgem como um recurso capaz de potencializar a reestruturação de práticas pedagógicas, criando novas maneiras de refletir sobre o uso da comunicação, da informação e da interação. (AUDINO; NASCIMENTO, 2010, p. 130)
\end{abstract}

O software JClic, como objeto de aprendizagem, foi utilizado neste estudo, porém, é de extrema importância relatar que a prática pedagógica, mediada pelo professor, potencializou e contribuiu para expressividade e criatividade de alunos matriculados na educação infantil, especialmente para aqueles com dificuldades de comunicação, como no caso o aluno com TEA.

\title{
Considerações finais
}

Por meio da inserção e intervenção realizada pela pesquisadora na sala de aula em que realizou o estágio curricular obrigatório do Curso de Licenciatura em Educação Especial, foi possível constatar a importância de se planejar com cuidado as atividades pedagógicas que foram desenvolvidas. É fundamental avaliar o quanto a atividade programada e o recurso tecnológico - software educativo - utilizado motivaram os alunos e, consequentemente, desencadearam o processo de ensino e de aprendizagem. 
Esse cuidado na elaboração da atividade e na escolha dos recursos, deve também levar em consideração outros aspectos pertinentes, como: a faixa etária dos alunos, o nível de interesse pela temática escolhida, suas aprendizagens já consolidadas e as que estão em vias de se consolidar, suas possíveis dificuldades, a dinâmica da sala de aula (o nível de colaboração e interação entre os pares), enfim, é preciso elencar com muita objetividade a intenção para a realização de determinada tarefa e a maneira como a essa intenção será avaliada. Em outras palavras, o professor precisa ter clareza do que pretende que seus alunos desenvolvam/aprendam e como avaliará se isso foi contemplado.

Pela atividade realizada, pode-se perceber também, que o objeto educacional utilizado - software JClic - proporcionou a interação entre os atores envolvidos na construção do conhecimento, servindo como um recurso para potencializar o processo de ensino e de aprendizagem e não apenas como um novo elemento educacional. Além disso, possibilitou o uso da expressão oral dos envolvidos, demonstrando que tiveram atenção para ouvir o som emitido pelos animais e conseguiram imitá-lo.

Sendo assim, tanto o objetivo geral, quanto os específicos da atividade foram cumpridos. Mais do que isso, a possibilidade de verbalizar e interagir por parte das crianças com diagnóstico de TEA e de dificuldades de comunicação na forma oral foram contempladas e apreciadas pelos demais colegas da sala.

A continuidade da observação promovida pela sequência do período de estágio demonstrou um crescente desenvolvimento nas habilidades comunicativas em ambos os alunos, sendo que o aluno G. passou a arriscar as produções de frases inteiras e a interagir com mais colegas, tanto em sala como em outros ambientes da escola. $\mathrm{O}$ aluno M., que anteriormente à intervenção não se expressava na forma oral, começou a pronunciar palavras curtas mediante solicitação e também ampliou e melhorou sua interação com colegas e adultos.

Pode-se dizer que por meio dessa atividade pedagógica, a interação entre as crianças ocorreu de um modo singular, abrindo possibilidades para novas intervenções e aprendizagens. Ainda cabe destacar que procedimentos que propõem metodologias e recursos inovadores e vão além do formato de ensino tradicional, podem promover um ambiente mais interativo e atingido melhores objetivos, sobretudo com alunos que demonstrem maiores dificuldade de aprendizagem.

RPGE - Revista on line de Política e Gestão Educacional, Araraquara, v. 21, n. esp.3, p. 1726-1735, dez., 2017. 


\section{REFERÊNCIAS}

AMERICAN PSYCHIATRIC ASSOCIATION, Manual diagnóstico e estatístico de transtornos mentais: DSM 5. Porto Alegre, RS: Artmed, 2014.

AUDINO, D. F.; NASCIMENTO, R. da S. Objetos de aprendizagem - Diálogos entre conceitos e uma nova proposição aplicada à Educação. Revista Contemporânea de Educação, Rio de Janeiro, vol. 5, n. 10, p. 128-148, jul/dez 2010.

BRASIL. Ministério de Educação e do Desporto. Referencial curricular nacional para educação infantil. Brasília, DF: MEC, vol. 1, 1998.

BRASÍLIA (DF). Decreto $\mathbf{n}^{\mathbf{7}} \mathbf{7 . 6 1 1}$ de 17 de novembro de 2011. Dispõe sobre a Educação Especial, o atendimento educacional especializado e dá outras providências. Diário Oficial da União, Poder Executivo, Brasília, DF, 18 de novembro de 2011Edição Extra.

GIL, A.C. Como elaborar projetos de pesquisa. São Paulo: Atlas, 2010.

LÜDKE, M; ANDRÉ, M. Pesquisa em Educação: abordagens qualitativas. São Paulo: EDU, 1986. CAp. 1 a 4 (p. 1-53)

MATOS, S.N.; MENDES, E.G. A proposta de inclusão escolar no contexto nacional de implementação das políticas educacionais. Práxis educacional, Vitória da Conquista, v. 10, n. 16, p. 35-59, jan-jun. 2014.

OLIVEIRA, V.B. (org). O brincar e a criança do nascimento aos seis anos. Petrópolis, RJ: Vozes, 2000.

PEDRO, K. M. Softwares educativos para alunos com deficiência intelectual: planejamento e utilização. 2012. 98f. Dissertação Mestrado em Educação, Faculdade de Filosofia e Ciências, Universidade Estadual Paulista, Marília.

UNESCO. Declaração de Salamanca. Sobre Princípios, Políticas e Práticas na Área das Necessidades Educativas Especiais. Espanha, 1994.

\section{Como referenciar este artigo}

GONÇALVES, Adriana Garcia.; PICHARILLO, Alessandra Daniele Messali.; PEDRINO, Mariana Cristina. Uso de objeto educacional digital na perspectiva da educação especial: relato de uma prática pedagógica. Revista on line de Política e Gestão Educacional, Araraquara, v. 21, n. esp.3, p. 1726-1735, dez., 2017. ISSN: 1519-9029.

Submetido em: 07/07/2017

Aprovado em: 10/08/2017 